are now hundreds of clinicians (nurse therapists, psychiatrists, psychologists) doing exposure therapy for OCD throughout the UK. UK purchasers of health care thus have a widely available option of choosing exposure therapy for OCD which is usually acceptable, inexpensive and more effective than is medication. The $30 \%$ or so of OCD sufferers who have concomitant depressed mood need both exposure and antidepressants.

Similar sidelining in the $B J P$ occurs when Tallis (1995) writes "Behaviour therapy remains the most effective and thoroughly evaluated psychological treatment of OCD" in a section actually devoted to "Cognition and cognitive therapy" and omits discussion of inexpensive yet effective self-exposure therapy. Readers and patients interested in such valuable self-exposure therapy may find it helpful to read Lee Baer's excellent book Getting Control (1991).

Baer, L. (1991) Getting Control. Boston: Little, Brown.

Piccinel.l. M., Pini, S., Bellantuono, C., et al (1995) Efficacy of drug treatment in obsessive-compulsive disorder. A metaanalytic review. British Journal of Psychiatrv, 166, 424443.

TAl.LIS, F. (1995) Reading about. . obsessive-compulsive disorder. British Journal of Psychiatry. 166, 546-550.

Institute of Psychiatry

I. MARKS

London SE5 8AF

\section{Clozapine-induced hypersalivation and the alpha2 adrenoceptor}

SIR: Hypersalivation can be a troublesome sideeffect of clozapine, limiting its usefulness in the management of some cases of schizophrenia (Fitton \& Heel, 1990), but the pharmacological basis of this remains obscure. As well as its action at several dopamine and serotonin receptor subtypes, clozapine can block muscarinic acetylcholine receptors and the alpha 2 adrenoceptor (Reynolds \& Czudek, 1995), which have opposing effects on the control of salivation. While muscarinic blockade leads to diminished salivary secretion, alpha2 antagonists can increase salivation (Berlan et al, 1992), suggesting that this latter action may underly clozapineinduced hypersalivation. To test this hypothesis, we administered the alpha2 agonist lofexidine to one patient in whom the side-effect was particularly distressing.

The 54-year-old man had suffered from chronic schizophrenia since 1959. In 1993 he was commenced on clozapine; the dose of clozapine was increased to $900 \mathrm{mg}$ per day and there were improvements in his social interactions, communi- cation and personal hygiene. Unfortunately he had severe hypersalivation which did not respond to thioridazine, procyclidine, or reduction in dose of clozapine to $600 \mathrm{mg}$ daily. With the addition of lofexidine $0.2 \mathrm{mg}$ b.d., there was a significant improvement in the hypersalivation, with nursing staff observing that the previously persistent dripping of saliva onto the patient's clothes quickly ceased. Because of the risks involved lofexidine was not continued for more than one month and it was subsequently necessary to discontinue the clozapine.

Lofexidine is an alpha 2 agonist which is licensed in the UK only for the short-term treatment of opiate withdrawal symptoms. It could not be used for long-term treatment without running the risks of depression and exacerbation of psychosis, which limited the usefulness of the similar agent clonidine in mania (Hardy et al, 1986), obsessive-compulsive disorder and Tourette's syndrome (Ashanuddin, 1982). However, awareness of the pharmacological basis of the hypersalivation may permit development of strategies to combat this limiting side-effect of a major antipsychotic.

Ashanuddin, K. (1982) Side-effects of clonidine (Letter). American Journal of Psychiatry, 139, 1083.

Berlan, M., Montastruc, J.-M. \& Lafontan, M. (1992) Pharmacological prospects for alpha2-adrenoceptor antagonist therapy. Trends in Pharmacological Science. 13, 277-282.

Fitton, A. \& Hees, R. C. (1990) Clozapine. Drugs. 40, 722-747.

Hardy, M.-C., Lecrubier, Y. \& Widlocher. D. (1986) Efficacy of clonidine in 24 patients with acute mania. American Journal of Psychiatry, 143, 1450-1453.

ReYnolds, G. P. \& Czudik. C. (1995) New approaches to the drug treatment of schizophrenia. Advances in Pharmacology. 32. $461-503$.

F. M. Corrigan

S. MACDONALD

Argyll \& Bute Hospital

Lochgilphead, Argyll

Scotland PA31 8LD

G. P. REYNOLDS

University of Sheffield

\section{Suspected congenital sertraline dependence}

SIR: We report the suspected occurrence of neonatal withdrawal symptoms from maternal use of sertraline throughout pregnancy, which as far as we are aware has not been previously reported. Withdrawal syndromes for sertraline, fluvoxamine and paroxetine have been reported to occur in adults (Szabadi, 1992; Louie et al, 1994; Pyke, 1995). 